\title{
226 EFFECT OF CARDIO-RESPIRATORY ENDURANCE, ANAEROBIC AND YOGASANA ON HDL AND LDL CHOLESTEROL LEVELS AMONG YOUNG MEN
}

Y Kalyan Kumar, ${ }^{1}$ V Jagannatha Reddy ${ }^{1}$ Government Junior College, Kurnool, Andhra Pradesh, India; ${ }^{2}$ Department of Physical Education, Government Degree College for Men, Kurnool, Andhra Pradesh, India

10.1136/bjsm.2010.078725.226

Objectives The purpose of the study to find out the effects of medium intensity cardio-respiratory endurance, anaerobic and selected medium intensity yogasana on the selected physiological factors which normally are considered as risk factors in the coronary heart disease, in healthy young males in the age of $18-22$ years.

Methodology Fifteen subjects were assigned to each of the four groups of experimentation by selecting the students on random basis and who volunteered. The groups were cardiorespiratory endurance group, anaerobic group and yogasana group. The training regimen consisted of clearly laid protocols of exercises for four different groups. For yogasana group, the protocol developed by Swami Shivananda of Rishikesh Ashram was used. Pre-training, resting HDL and LDL cholesterol levels and post-training values were measure and analysis of covariance statistical technique was used to analyse the results.

Results Medium intensity cardiorespiratory endurance training brought more significant increase in HDL cholesterol levels, though all the three types of protocols brought significant increase in the resting HDL cholesterol. Medium intensity cardiorespiratory endurance training brought more significant reduction in LDL cholesterol levels, though all the three types of protocols brought significant reduction in the resting LDL cholesterol. 